\title{
DEVELOPMENT STATUS OF SUSTAINABLE URBAN MOBILITY PLANS IN EUROPEAN UNION NEW MEMBER STATES
}

\author{
DANA SITÁNYIOVÁ \& SOŇA MASAROVIČOVÁ \\ Department of Geotechnics, University of Žilina, Slovakia.
}

\begin{abstract}
Local authorities in European cities are seeking new approaches to develop strategies that help stimulate a shift towards cleaner and more sustainable transport modes. Sustainable Urban Mobility Plans (SUMPs) are instruments that contribute towards achieving climate and energy targets set by European Union (EU) leaders and promoted through the European Commission (EC) in relevant documents such as the Transport White Paper and Action Plan on Urban Mobility. A well-prepared SUMP will help to provide high-quality and sustainable mobility and transport to, through and within urban areas. SUMPs foster a balanced development of all transport modes, while encouraging a shift towards more sustainable modes and usage. The plans present both long-term strategies for the future development of transport and mobility infrastructure and services in urban areas as well as short-term plans for implementation of these strategies: timing, allocation of resources and responsibilities and identifying the required finances. They include integrated sets of technical, infrastructure, policy-based and soft measures. Different approaches to sustainable urban mobility planning exist throughout Europe. While some countries, such as France and the UK, may be considered forerunners (with plans produced under a different name and slightly different methodology), SUMPs are a new planning tool in other parts of the EU, especially within the new member states. This article presents the way in which the SUMP concept was introduced and accepted in Slovakia.

Keywords: audit, mobility, plan, strategy, sustainable, transport, urban area.
\end{abstract}

\section{INTRODUCTION}

The European Commission's (EC) White Paper on Transport - published in 2001 - recognized that the smooth flow of transport was fundamental to the European economy and society, with mobility being vital for the internal market and for the quality of life of citizens. Transport needed to be sustainable in the light of the new challenges being faced. Since then, much has been achieved, with the Single European Sky being successfully launched; the rapid improvement of the safety and security of transport across all modes; Trans-European transport networks having contributed to territorial cohesion; and great efforts made to enhance transport's environmental performance. However, the transport system is still not fully sustainable and many transport and land use models of today have not yet responded to the new challenges the European Union (EU) faces. Looking 50 years ahead, it is clear that transport cannot continue to develop along its current path [1]. Many mobility problems in transport remain, with cities continuing to suffer from congestion, poor air quality and noise exposure. Urban transport is responsible for about a quarter of $\mathrm{CO}_{2}$ emissions from transport, and the percentage of road accidents that occur in cities remains dangerously high at $69 \%$ [1].

The high concentration of economic activities in cities means that they are complex spatial structures that require functional and supportive transport systems. Many current transport systems, for a variety of reasons, cannot satisfy the numerous requirements of urban mobility. The larger the city, the greater its complexity and the potential for disruption. Often this complexity is not effectively managed, especially the preparation of necessary new policies, such 
as the promotion of more energy-efficient vehicles or alternative fuels, support for public transport, transport demand management or anti-sprawl legislation. Recognizing the continuing problems of urban mobility, the EC adopted the Action Plan on Urban Mobility in 2009. This proposed short- and medium-term practical actions to be launched, addressing specific issues related to urban mobility in an integrated way. It listed six themes, with Theme One including direct reference to 'Accelerating the take-up of sustainable urban mobility plans'. At the core of mobility management are so-called soft measures such as information, communication, improved service promotion and activities that relate to mentality change of transport users. Soft measures are typically used to enhance the effectiveness of so-called hard infrastructure measures. The Action Plan proposed measures to encourage and help local, regional and national authorities in achieving their goals for sustainable urban mobility. The Commission has actively promoted this concept for several years, but it is the member states that need to promote these practices at the national level and ensure that the right legislative and support conditions are in place for local authorities. Unfortunately, many transport and land use models have not yet responded to these new challenges. This is especially so in the EU new member states (Estonia, Latvia, Lithuania, Poland, Czech Republic, Slovakia, Slovenia, Croatia, Hungary, Bulgaria and Romania) where there remains an entrenched mentality of planning based on old and outdated methods, materials and management.

\section{SUSTAINABLE URBAN MOBILITY PLANS}

A Sustainable Urban Mobility Plan (SUMP) is a strategic plan designed to satisfy the mobility needs of people and businesses in cities and their surroundings for a better quality of life. It builds on existing traditional planning practices of individual countries, but also takes due consideration of integration, participation and evaluation principles. A SUMP aims to create a sustainable urban transport system by addressing some, if not all, of the following objectives:

- Ensure transport system accessibility for all;

- Improve safety and security;

- Reduce air and noise pollution, greenhouse gas emissions and energy consumption;

- Improve the efficiency and cost-effectiveness of the transportation of persons and goods;

- Enhance the attractiveness and quality of the urban environment.

SUMPs gained increased recognition and importance at the European level when the EC launched several documents and strategies to support this concept, among the most important being the Action Plan on Urban Mobility (2009) and the Transport White Paper (2011). The EC had previously also examined the possibility of a mandatory take-up of SUMPs for cities of a certain size.

Two EU-supported projects that provided a big impact to the promotion and take-up of SUMPs were ELTIS plus (in establishing an implementation methodology) and ADVANCE (establishing a pre- and post-SUMP assessment methodology). The ELTIS plus project supported by EC funds has highlighted the benefits of SUMPs in comparison to traditional transport plans. The specific goals of the project were to raise awareness of SUMPs and to provide guidance and training materials for urban mobility professionals all over Europe. ELTIS plus has been implementing two inter-related activities: the management of the European Local Transport Information Service web site, www.eltis.org, and the promotion of the uptake of SUMPs across all member states. 


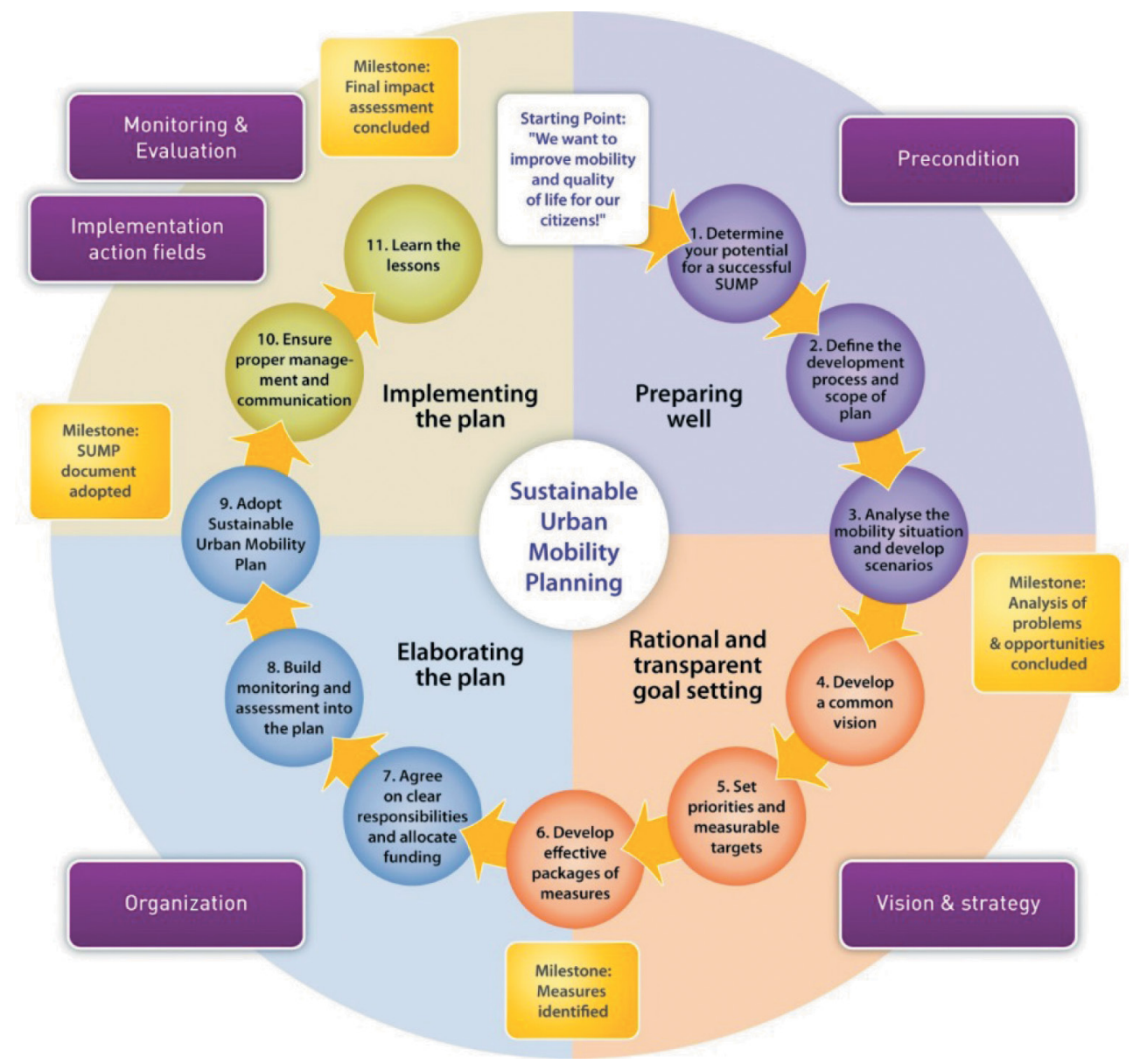

Figure 1: SUMP cycle (Source: ELTIS plus [2] and ADVANCE [3]).

The policies and measures defined in a SUMP should cover all modes and forms of transport in the entire urban inner and outer areas, including public and private, passenger and freight, motorized and non-motorized, moving and parking. A result of the project was the production of guidelines for the minimum requirements of the preparation and implementation for a quality SUMP [2]. According to ELTIS plus [2] and ADVANCE [3], full SUMP cycle includes four main phases (Fig. 1):

1. Preparing well for the planning process;

2. Rational and transparent goal setting;

3. Elaborating the plan;

4. Implementing the plan.

The SUMP cycle consists of 11 Elements (main steps) and 32 Activities (detailing specific tasks) providing a logical rather than a sequential structure. The important element to consider is the repetitive process of elaboration of the plan; it needs to be applied not as the summative result of successive stages of studies, but rather an integrative process that allows a shared diagnosis of the situation, a progressive definition of objectives and the consistency of means. 
Bearing in mind that the SUMP should be a way of tackling transport-related problems in urban areas more efficiently, it is wise to build upon existing practices and regulatory frameworks. Therefore, the following basic characteristics need to be considered:

- A participatory approach: citizens and stakeholder involvement from the start and throughout the process in all decision-making, implementation and evaluation, building local capacity for handling complex planning issues and ensuring gender equity;

- A pledge for sustainability: balancing economic development, social equity and environmental quality

- An integrated approach: mixing practices and policies between policy sectors (e.g. transport, land use, environment, economic development, social inclusion, gender equity, health, safety), between authority levels (e.g. district, municipality, agglomeration, region, nation, EU) and between neighbouring authorities (inter-municipal, inter-regional, transnational, etc.)

- A focus on a clear sustainable development strategy: achieving measurable targets derived from short-term objectives, aligned with a vision for transport

- An economic review: emphasis on transport costs and benefits, taking into account wider societal costs and benefits, and also across policy sectors

Because SUMPs build upon already established and traditional transport planning practices, it is important to understand and recognize the main differences between the two - indicated in Table 1 .

Table 1: The differences between traditional transport planning and SUMPs.

\begin{tabular}{|c|c|}
\hline Traditional transport planning & Sustainable Urban Mobility Planning \\
\hline Focus on traffic & Focus on people \\
\hline $\begin{array}{l}\text { Primary objectives: traffic } \\
\text { flow and speed }\end{array}$ & $\begin{array}{l}\text { Primary objectives: accessibility and quality of life, sus- } \\
\text { tainability, economic viability, social equity, health and } \\
\text { environmental quality }\end{array}$ \\
\hline Modal focused & $\begin{array}{l}\text { Balanced development of all relevant transport modes } \\
\text { and shift towards cleaner and more sustainable transport } \\
\text { modes }\end{array}$ \\
\hline Infrastructure focus & Integrated set of actions to achieve cost-effective solutions \\
\hline Sector planning document & $\begin{array}{l}\text { Sector planning consistent with and complementary to } \\
\text { related policy areas }\end{array}$ \\
\hline $\begin{array}{l}\text { Short- and medium-term } \\
\text { delivery plan }\end{array}$ & $\begin{array}{l}\text { Short- and medium-term delivery plan embedded in a } \\
\text { long-term vision and strategy }\end{array}$ \\
\hline $\begin{array}{l}\text { Related to an administrative } \\
\text { area }\end{array}$ & $\begin{array}{l}\text { Related to a functioning area based on travel-to-work } \\
\text { patterns }\end{array}$ \\
\hline Domain of traffic engineers & Interdisciplinary planning teams \\
\hline Planning by experts & $\begin{array}{l}\text { Planning with the involvement of stakeholders using a } \\
\text { transparent and participatory approach }\end{array}$ \\
\hline Limited impact assessment & $\begin{array}{l}\text { Regular monitoring and evaluation of impacts to inform } \\
\text { a structured learning and improvement process }\end{array}$ \\
\hline
\end{tabular}

(Source: ELTIS plus [2]) 


\section{INTRODUCING THE SUMP CONCEPT IN SLOVAKIA}

\subsection{PESTLE analysis}

The PESTLE analysis is a framework used to scan the organization's external macro environment. PESTLE analysis was performed by the authors of this article in 2015 as a useful method to identify the external factors that influence urban mobility planning in Slovakia, together with an interview survey among 55 stakeholders, including decision-makers, policy influencers, practitioners, academia and others. The analysis was done for use in EVIDENCE project (http://evidence-project.eu/), supported by the EC, seeking to find the credible evidence that can be used to substantiate the benefits of greater investment in sustainable transport. This will help politicians and transport practitioners understand the economic return on investment that can be achieved through increasing expenditure on sustainable transport. The main results of the analysis can be summarized as given below.

Political: Generally, there is a political will in Slovakia oriented towards sustainable mobility with several policy papers in place to support this - the most important being Transport Development Strategy to 2020 and the EU Operational Programme - which provides a strategic funding document for EU funds received for the 2014-2020 period. The main goals of these funding programmes are to improve accessibility, reduce regional disparities and support economic development, while also reducing the negative impacts on the environment and on public health. These EU funds are the cornerstone of Slovakia's medium- and long-term development strategy and they should also mobilize additional public national and private funding for sustainable mobility. Significant attention is given to the territorial dimension of interventions, particularly in the area of urban development and access to public services. At least 5\% of the European Regional Development Fund allocation in Slovakia will be invested in sustainable urban development actions implemented in regional capital cities and their functional areas.

In local politics, mobility has also become one of the main issues and residents express their interests and concerns during public consultation processes organized by municipalities. In line with this political awareness among citizens, civil society has also gradually increased its power, particularly in the last decade. There are many active non-governmental organizations (NGOs) focusing on sustainable mobility organizing campaigns and events supporting changes in travel behaviour and shifts to more sustainable travel modes (among others MULICA, PEDAL, OCIBB, Cycling coalition, Kostitras, Malacky na kolo).

Economic: In previous years, a lack of funding was considered the most significant barrier to implementing mobility measures in Slovakia, a situation particularly bad in the cities with the majority of city representatives claiming to have very limited funding sources. The municipal income and state subsidies cover only minimal maintenance of existing infrastructure and public transport services. Only a bare minimum of city budget is used for new sustainable mobility measures (somewhere between 0 and 4\%). Those cities with the relevant staff resources to apply for EU funds do so, making many cities wholly dependent on EU funds, donors or other EU projects (e.g. Horizon 2020). A weak economic base is the main reason for cities' lack of improvement in sustainable mobility measures. If more funding was available, the potential to shift cities towards the implementation of mobility measures would increase rapidly.

Social: Social changes in Slovakia are increasingly affecting mobility. In close interaction with social values and individual attitudes, mobility patterns are linked in complex ways to significant social trends, such as the adoption of suburban life style or ageing of the 
population. It is increasingly evident that the corresponding new lifestyle in societies and the mobility behaviour associated with such lifestyle are not consistent with protection of environmental quality or promotion of social cohesion.

Although there is a general consensus among citizens that sustainable mobility is beneficial, many nevertheless are not prepared to make the personal changes necessary to their travel habits. Therefore what is needed is a better understanding of the constraints upon, and drivers of, mobility behaviour. Generally, citizens are not very interested in the actual mobility planning process, but are interested in what mobility measures are implemented in their neighbourhood or city. They will often support small mobility interventions such as cycling infrastructure, pedestrian paths or changes in the quality or frequency of public transport services.

European Mobility Week (EMW) campaigns, games and other activities contributed to a substantial increase in cyclists in Slovak cities (e.g. 7\% increase of total number in average in Žilina each year during the last five years, or 52\% annual increase boom in Bratislava (2012/2013)). Cycle to Work or Cycle to School campaigns have been achieving increased popularity year by year. Public awareness has been rising and citizens are no longer considered only as users, but also as key stakeholders. This has also made politicians in cities support implementation of measures for cyclists (new lanes, racks, access to one-way roads or pedestrian areas).

Technological: In interviews mobility experts and municipal staff articulated mobility both as a critical difficulty and a potential source of hope to transform city operations. There is a need to treat mobility as a tool to enhance economic, social and environmental wellbeing. Significant investment will be required for solutions using new technologies which can be used to take positive steps to transform mobility systems. The technologies and services that enable smarter mobility have a range of capabilities which benefit travellers, service providers and urban planners alike. Some of them have already been introduced in Slovak cities including:

- Dynamical junction management (Bratislava, Žilina, Košice, Prešov, Trnava);

- Prioritization for public transport (Žilina, Bratislava);

- Dynamic weighting and toll system (highways);

- Navigation parking system (Bratislava, Košice);

- Information system for public transport (Žilina, Bratislava, Košice);

- Monitoring systems (traffic counters and air pollution).

However, this is still not enough and cities should consider a stronger focus on the smart city concept and the benefits of employing more integrated technological measures. Concerning e-mobility, the Slovak government does not presently support this and it is difficult to bring electric vehicles to the Slovak market and promote electromobility.

Legislative: In the Slovak Republic, public administration is provided by state administration (central government) and territorial self-government (sub-national government). These two components of public administration are independent, but they cooperate. The Slovak Republic consists of eight self-governing regions, their governing being in principle independent from the central government. EU funds and national funding are managed by the relevant ministries and the managing authority of the particular operational programme.

The current situation in mobility planning at the regional level can be characterized as follows. Regional governments still suffer from some deficiencies. Governance mechanisms, 
processes and methodologies for decision-making processes are inefficient and ineffective; there is a lack of knowledge and skills in the field of transport planning and regional development; there is insufficient cooperation between entities vested with co-responsibility for regional mobility policies. At a city level, there is a growing understanding of what might constitute a more sustainable urban transport policy, but there are still serious barriers to implementing such policies. In particular, much can be done to improve the planning process at municipalities, policy formulation, the involvement of stakeholders, the effective use of information and skills and the appropriate application of finance.

Prioritization of measures is often chaotic at all levels and influenced by many aspects such as power and activities of individuals in committees and municipal councils, land ownership rights, financial claims, expected impact, available financial sources (EU funds), population density, safety problems, congestion problems and many others. The majority of measures tend to be realized in pre-election periods. Development and modernization of transport infrastructure and services, and prioritization and implementation of individual measures should be based on cost-benefit analysis reflecting the results of strategic analyses, as well as on communication with relevant stakeholders and the public. Therefore achieving pre-project consultation will be a crucial challenge in the coming years in Slovakia. Ex post evaluations and assessment to verify results of projects after their implementation should also become a routine part of the planning process.

Environmental: The inhabitants of larger cities - as well as those villages with large transit transport - have the greatest exposure to excessive noise levels. Progress has been made since 1995, with complex noise monitoring being carried out in all district cities. Authorities were also required to elaborate strategic noise maps for main roads, railways, airports and agglomerations, as well as to develop action plans for noise reduction. Further strict environmental criteria have forced some Slovak cities such as Banská Bystrica, Žilina, Bratislava, Košice and Prešov to 'clean up' their public transport fleet through the purchase of hybrid buses, trams, trolleybuses and natural gas buses.

All the larger cities also have air quality monitoring systems in city centres paid for by the state and operated by the Slovak Hydrometeorological Institute. The largest contribution to the pollution of air is that of the chemical industry, energetics and transport. The significant secondary source of air pollution in cities is secondary dustiness, the level of which depends on meteorological factors, earthwork, agricultural work and the character of the surface. Thanks to the legislative and technological measures in air protection, there is a marked decrease observed in the amount of the basic pollutants in recent times. The development of sustainable urban mobility also supported the use of using funds directly aimed at climate protection and energy efficiency from the Slovak Operational Programme 'Transport' within the frame of Priority axis 3 'Intermodal transport infrastructure'.

\subsection{The latest development}

Before 2013, as a result of the EMW campaigns and involvement of Slovak partners in European projects, some municipalities, particularly those in the bigger cities (Bratislava, Žilina, Košice, Prešov, Banská Bytrica), started to use sustainable mobility measures to improve their urban transport systems. However, still missing were the appropriate tools and methodologies. The introduction of the SUMP concept started with the help of several EU projects. The main aim of the projects was to embed Mobility Management and SUMPs into regional and municipal transport policies and bring mobility measures into practice. In these projects, 
cities usually learnt from the experience of more advanced project partners from Europe. Themes covered included how to improve public transport, cycling, parking, walking and the environment in their cities. Košice and Žilina were the first two Slovak cities to prepare their mobility action plans in 2013 and 2014, respectively. Before 2013, the status of SUMPs with regard to city acceptance and awareness can be summarized as follows:

- Bigger Slovak cities were informed about the SUMPs concept;

- Cities declared a general interest in SUMPs;

- Cities started to implement some ad hoc measures related to mobility management and mobility planning;

- There was not a systematic approach in this field at the national level;

- There was not an appropriate collaboration established between cities and relevant stakeholders.

However, the understanding of the possible and actual effects of SUMPs on the real mobility situation in cities was still rather limited in Slovakia. This fact together with the lack of available funds proved to be the most crucial barrier in obstructing more progress in developments. Another gap was a fragmentation of sources and carriers of progress. The carriers of progress, especially representatives of NGOs, cycling initiatives, academia, mobility and transport experts worked in individual ways. Many times they did not know each other's work. This lack of cooperation and knowledge of the right hand not knowing what the left hand was doing were also evident within the levels of local government.

In 2015 the Ministry of Transport, Construction and Regional Development and the Ministry of Agriculture and Rural Development of the Slovak Republic with the help of Slovak experts and Jaspers prepared a Methodology for SUMP development for regions and cities. Based on the conventional ELTIS Sustainable Urban Mobility Plan process, it also added specific elements tailor-made for national conditions. Since only the cities of Bratislava and Košice have populations of over 100,000 (a limit stated in EU guidelines for SUMPs), the guidelines were modified for Slovak conditions in order to also cover the smaller cities and towns.

The latest achievement has been the decision to assign a part of its EU Cohesion funds for the development of SUMP documents and other mobility strategies as well as for the implementation of sustainable mobility measures based on them. This programme was launched at the end of 2015 and is co-financed by an Operational programme for implementation of European cohesion policy in the period 2014-2020. It is expected that the SUMPs concept will be implemented at several different levels - at regional level in the capital cities of the eight self-governing regions, in cities with over 50,000 inhabitants, but also in small municipalities. Five cities have already decided to follow the programme. Most of the credit for this goes to the past or ongoing financial support from EU mobility projects (i.e. IEE programmes or South East Europe Transnational Cooperation Programme) and recently to the seven-year Cohesion Programme funds which now seem to represent a basic backbone for the future development of SUMPs in Slovakia.

The EU-funded project ADVANCE (IEE project, http://eu-advance.eu/\#1) further helped Slovak cities and experts to be better prepared for SUMPs. Through this project, there are now 18 experts trained as ADVANCE auditors to perform audits of mobility plans and planning practices in Slovak cities. Also within national involvement in the EU ENDURANCE project (IEE project, http://www.epomm.eu/endurance/index.php), events such as national 
meetings, workshops and trainings were organized to assist cities and regions with developing SUMPs. The main target groups of project activities were urban mobility professionals, cities and regional and national authorities. They gained new knowledge and insights into how to deliver an improved approach to transport planning. The ENDURANCE SUMP national network became a part of CIVINET Czech and Slovak Republic providing an efficient and lasting supporting structure for production of the SUMP documents.

\section{CASE STUDY - RUŽOMBEROK}

Ružomberok is a town in northern Slovakia with a population of around 30,000 (45,000 including nearby villages). It is the capitol of the Liptov sub-region stretching over an area of $1,970 \mathrm{~km}^{2}$. Liptov is among the most popular touristic region of Slovakia, as it contains the territories of three national parks. Ružomberok is famous as an industrial town. It is also an important transport junction lying on the 1st class roads E-50 and E-77. E50 is one of the roads with the highest traffic intensity in Slovakia (Ružomberok - 29,233 cars/day in 2010). This transit road is also a part of the town's overall road network. Traffic congestion on the main junctions continues to be a major problem in the town resulting in massive delays, increased fuel wastage and monetary losses. The resultant pollution is one of the biggest challenges facing the town (Fig. 2).

Ružomberok started to develop its SUMP in September 2015 and the work will continue during the first half of 2016. The first step was independent validation of its urban mobility performance and sustainability by ADVANCE audit. The aim of the audit is to assess and improve the quality of the mobility planning and policy in the city, as well as to analyse, systemize and improve the whole process of the development of the SUMP. These 'process' elements are analysed by the Mission Fields; the implementation of measures and actions in the city is analysed by the Action Fields. The process follows five steps as represented in Fig. 3.

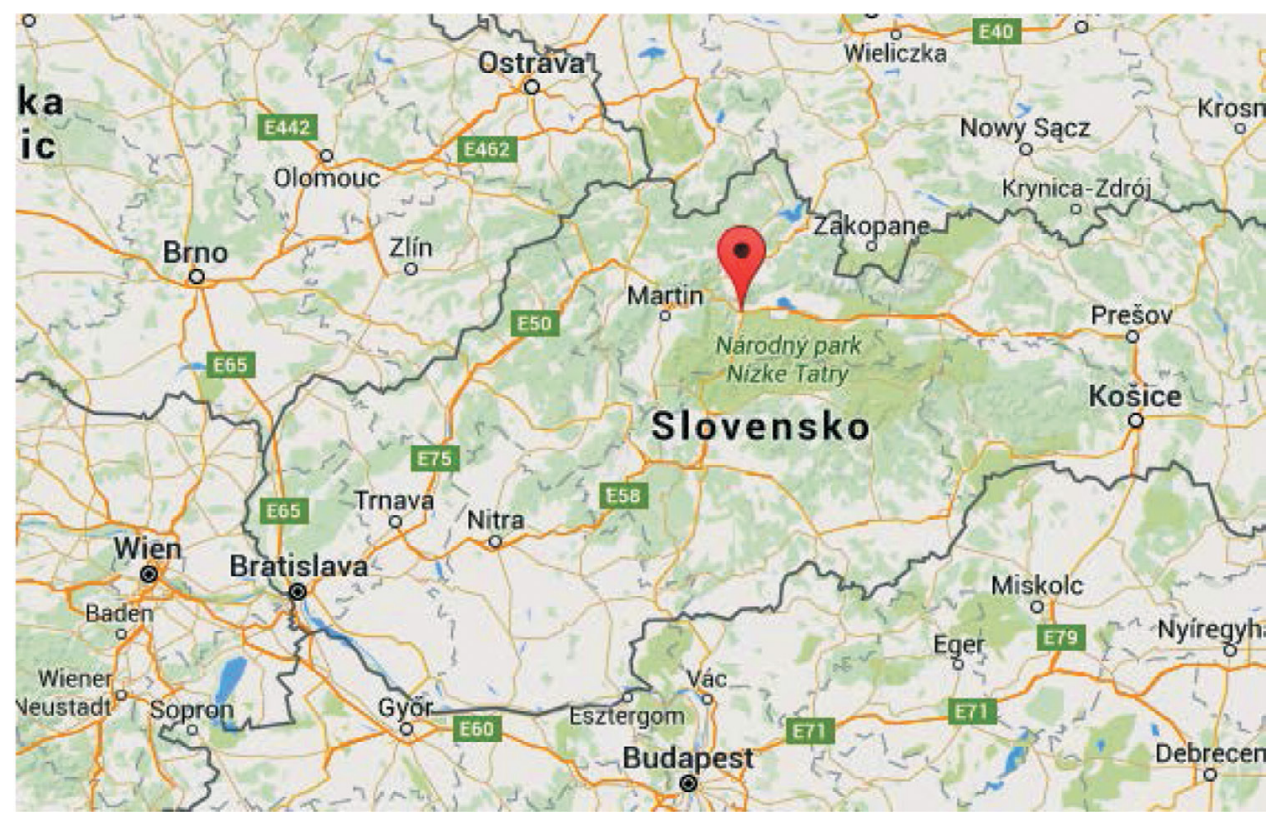

Figure 2: Location of Ružomberok. 


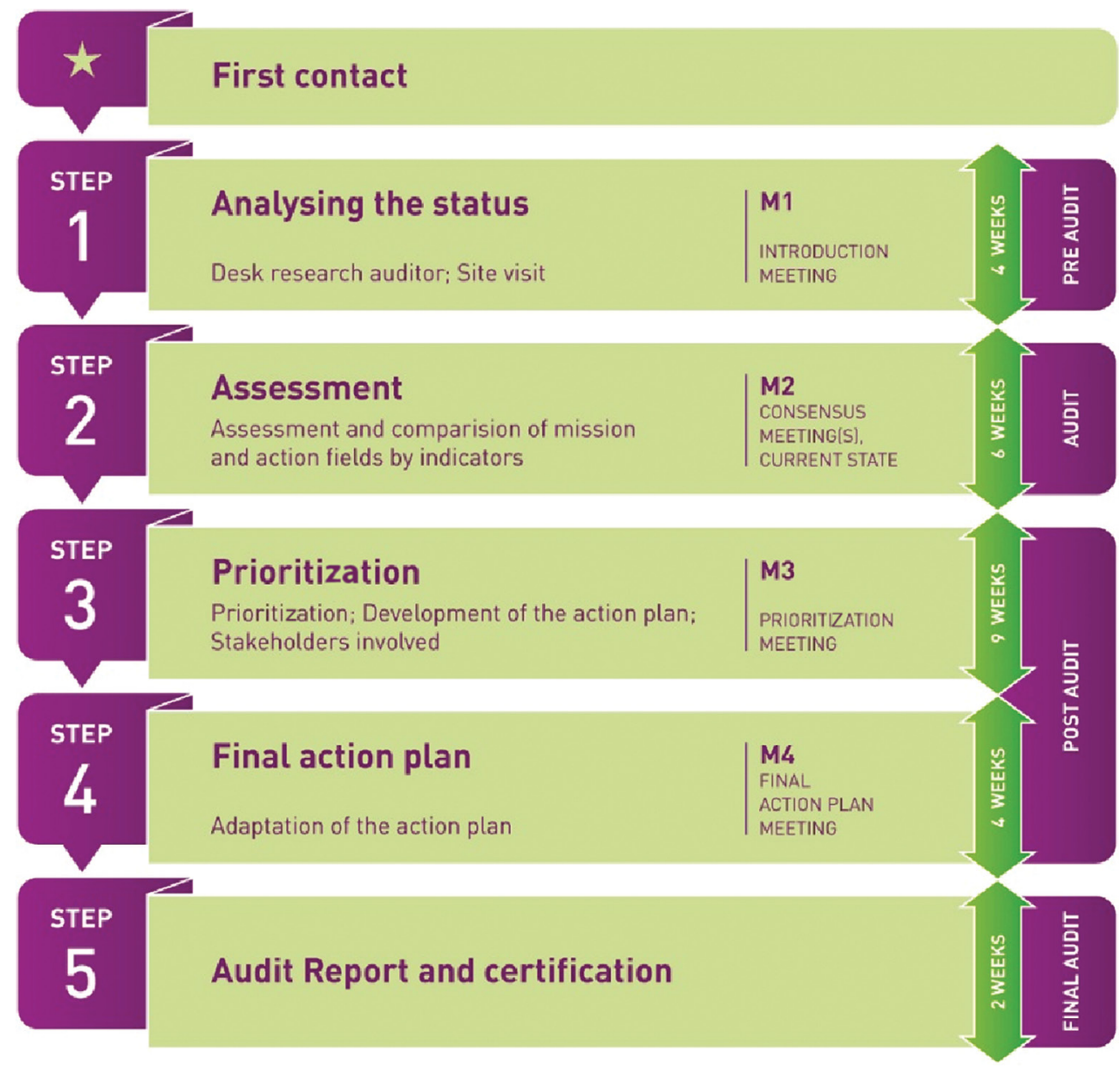

Figure 3: ADVANCE audit scheme (Source: ADVANCE [3]).

A meeting between two certified auditors and the town representatives was organized. The auditors clearly explained their role as facilitators of the audit process and described the necessary capabilities and resources that were required to compose the ADVANCE working group. Special emphasis was put on the involvement of relevant stakeholders. The auditors collected context indicators, researched the relevant city documents and carried out a site visit to the city, which helped to determine the baseline situation of the city.

The working group as the main actor in the audit process was established. It was formed to discuss strengths and weaknesses of the urban mobility planning and to define ways for further improvement. In Ružomberok the working group was composed of 12 internal and external members. Its composition reflects the departments within the city and the relevant stakeholders that are responsible for the functions covered by the mission and action fields. The working group includes people responsible for land use planning and for transport financing, strategic development, the public transport operator, infrastructure responsible actors, representatives of the town's biggest employers, university, cycling association, police, councillors for transport and mobility and NGO supporting sustainable development. 


\section{Processes by individual respondents}

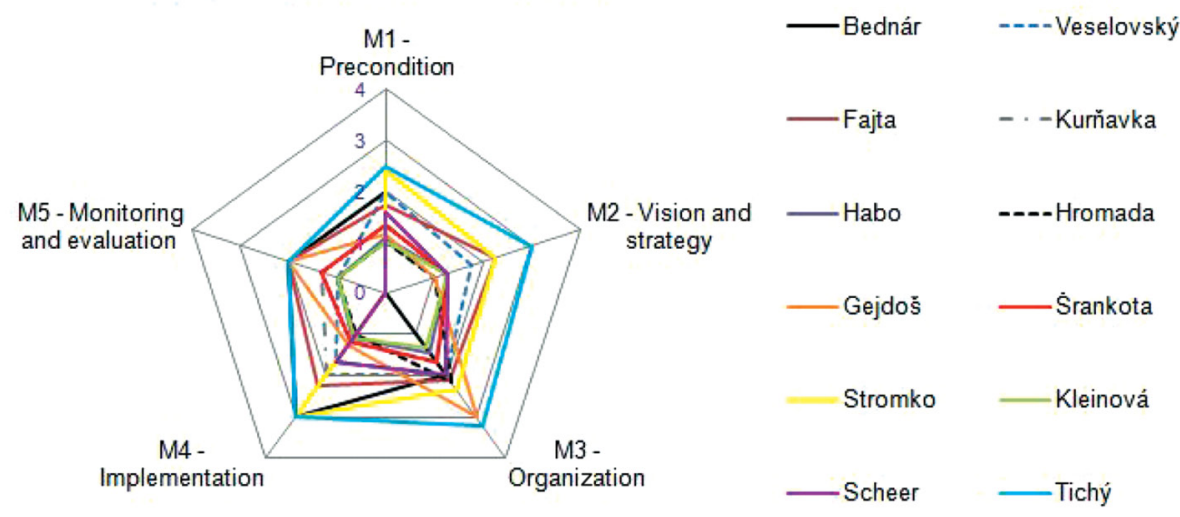

Action fields by respondents

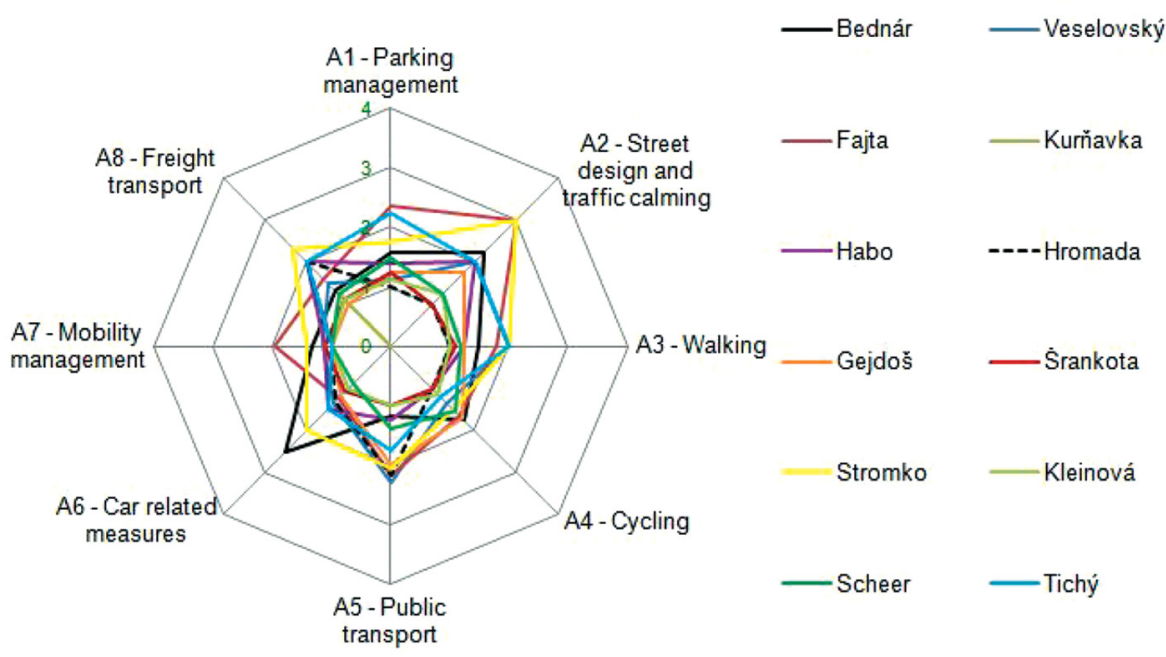

Figure 4: Results of survey (Source: [4]).

The vice mayor, as an important political actor, is also a member of the group to show the political commitment of applying the ADVANCE Audit.

During the first meeting the auditors explained all the details of the audit process. Special attention was given to the role and expectations of all participants. After the meeting auditors distributed the ADVANCE questionnaire. The members of the working group completed the questionnaire individually. The ADVANCE questionnaire is the main instrument to perform the assessment covering the five Mission Fields and the eight Action Fields with 131 questions. All answers were collected, summarized and analysed by the auditor to prepare the consensus meeting. The scoring for the different mission and action fields by individuals in working group is presented using cobweb diagrams (Fig. 4).

The results are assessed on a scale from level 1 to 4 . Level 4 indicates the highest level of performance or implementation and level 1 the lowest. During the second meeting in plenary discussions a consensus on the score of answers was sought for every mission and action field. 
According to ADVANCE audit methodology, Ružomberok's total average score of $39.5 \%$ ranks it among 'starting cities'. For starting cities the ADVANCE Audit provides a first moment of consideration and reflection on sustainable urban mobility planning with assistance from a certified auditor. All information gathered during consensus meetings helped the city to prepare the priority list of possible improvements/actions and plan further analyses. The ADVANCE Audit will result in an action plan that will form the basis for the full development of a SUMP.

\section{CONCLUSIONS}

The need for more sustainable and integrative urban planning processes has been widely recognized across Europe, especially so in Central and East European member states. At the European level, Sustainable Urban Mobility Plans have gained increased recognition and importance in recent years. On the basis of the knowledge consolidation in the context of the ELTIS plus project, guidelines on 'Developing and Implementing a Sustainable Urban Mobility Plan' were published in 2011. Many member states including Slovakia have prepared their national guidelines or methodologies considering specific country conditions. In Slovakia the new planning culture, with the help of European ADVANCE and ENDURANCE projects, has been introduced supporting a holistic approach moving away from engineering-based and infrastructure-based approaches to an approach integrating all relevant sectors, disciplines and decision-making levels. This can be considered a major success and will be instrumental in ensuring SUMPs are effectively developed and successfully implemented. The ADVANCE audit has proved to be an effective and low-cost tool that analyses the strengths and weaknesses in the current sustainable mobility planning of Slovak cities. However, the benefits and added value of SUMPs including cost and benefits need to be continually communicated especially to politicians, decision-makers and urban mobility stakeholders to encourage their preparation and implementation. The Slovak National SUMP network will deliver training in different formats consisting of combinations of awareness raising, technical training and exchange of experience, targeted at representatives of authorities who are to be involved in the preparation of Sustainable Urban Mobility Plans.

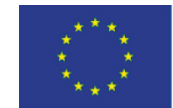

Co-funded by the Intelligent Energy Europe Programme of the European Union

\section{LEGAL DISCLAIMER}

The sole responsibility for the content of this article lies with the authors. It does not necessarily reflect the opinion of the European Union. Neither the EACI nor the European Commission is responsible for any use that may be made of the information contained therein.

\section{REFERENCES}

[1] European Commission (EC), WHITE PAPER roadmap to a single European transport area - towards a competitive and resource efficient transport system. Brussels, 2011, available at http://eur-lex.europa.eu (accessed 11 December 2015).

[2] ELTIS plus, Guidelines. Developing and implementing a sustainable urban mobility plan (working document part of Deliverable 2.2), available at www.mobilityplan.eu, 2011 (accessed 11 December 2015).

[3] ADVANCE project, Final ADVANCE audit scheme and guidelines, available at http:// eu-advance.eu/docs/file/d2_5_final_advance_audit_scheme_including_guidelines_ en.pdf, 2014 (accessed 11 December 2015).

[4] Sitanyiova Dana, Gogola Marian. Intermediate audit report for Ružomberok, 2015. 